\title{
Extreme Walrasian Dynamics: The Gale Example in the Lab
}

\author{
By Sean Crockett, Ryan Oprea, And Charles PlotT
}

\begin{abstract}
We study David Gale's (1963) economy using laboratory markets. Tatonnement theory predicts prices will diverge from an equitable interior equilibrium toward infinity or zero depending only on initial prices. The inequitable equilibria determined by these dynamics give all gains from exchange to one side of the market. We show surprisingly strong support for these predictions. In most sessions one side of the market eventually outgains the other by more than 20 times, leaving the disadvantaged side to trade for mere pennies. We also find preliminary evidence that these dynamics are sticky, resisting exogenous interventions designed to reverse their trajectories. (JEL C92, D50)
\end{abstract}

$[F]$ or the case of two goods, one always has global stability. ... Nevertheless, some queer things can happen even in this case.

— David Gale (1963)

General equilibrium theory is a cornerstone of modern economics and our core account of the nature of competitive markets. The theory has usually been focused more on the existence and character of competitive equilibrium, however, than on how, when, and why economies come to be in equilibrium. Given the computational and epistemic requirements for calculating a competitive equilibrium, it seems implausible that economic agents could ever "think" their way there. More likely, dynamic processes govern disequilibrium prices, guiding them toward or away from equilibria. Until and unless we understand these dynamic processes, it is difficult to assess general equilibrium theory's usefulness for predicting and explaining the behavior of competitive markets.

On this front there has been no shortage of theory. Accounts of disequilibrium dynamics stretch back to Marie-Esprit-Léon Walras (1877), and the quest for a

\footnotetext{
* Crockett: Department of Economics and Finance, Zicklin School of Business, Baruch College (City University of New York), 55 Lexington Avenue, Room 10-277, New York, NY 10010 (e-mail: sean.crockett@baruch.cuny. edu); Oprea: Economics Department, University of California-Santa Cruz, 1156 High Street, Santa Cruz, CA 95064 (e-mail: roprea@ucsc.edu); Plott: Division of the Humanities and Social Sciences, 228-77, California Institute of Technology, Pasadena, CA 91125 (e-mail: cplott@hss.caltech.edu). We thank three anonymous referees, Omar Al-Ubaydli, Dan Friedman, Stephen Spear, Steve Gjerstad, Bart Wilson, seminar participants at Baruch College, participants at the 2009 Economic Science Association North American Regional Meeting, and participants at the ninth Society for the Advancement of Economic Theory Conference. We also thank Paul J. Brewer, Hsing Yang Lee, and Travis Maron for developing the laboratory market system we used to conduct our experiment (see http:// marketscape,caltech.edu/wiki for details). For financial support, Crockett thanks the City University of New York through PSC-CUNY award 60095-3738. Plott thanks The Gordon and Betty Moore Foundation and the Caltech Laboratory for Experimental Economics and Political Science.

${ }^{\dagger}$ To view additional materials, visit the article page at http://www.aeaweb.org/articles.php?doi=10.1257/aer.101.7.3196.
} 
satisfying theory was an active pursuit until the 1970s (e.g., Frank H. Hahn and Takashi Negishi 1962; Leonid Hurwicz, Roy Radner, and Stanley Reiter 1975; Hirofumi Uzawa 1962) when it died off arguably for want of empirical nourishment. ${ }^{1}$ Modern observers have wondered whether existing theories of dynamics are empirically meaningful, given that they are typically founded on some variation of tatonnement, a centralized price adjustment mechanism that differs substantially from most naturally occurring markets. In a wide-ranging survey, Darrell Duffie and Hugo F. Sonnenschein (1989) conclude that because actual market prices are not determined by the tatonnement mechanism, "few would argue today that it is a useful way to select from Walrasian equilibria."

Recently, laboratory research has stepped in to fill the empirical gap (e.g., Plott 2000, 2001; Christopher M. Anderson et al. 2004, Masayoshi Hirota et al. 2005; Steven Gjerstad 2007), and findings have in fact been broadly supportive of Walras's hypothesis that price dynamics are intimately related to, and driven by, a market's excess demand. ${ }^{2}$ Moreover, this literature suggests that Walrasian notions of dynamics and stability have predictive power, even in distinctly nontatonnement market institutions (virtually all of this literature uses the double auction institution). 3

In this paper we provide a particularly strong test of the Walrasian hypothesis by experimentally studying a simple economy in which Walrasian dynamics predict highly implausible outcomes. In the Gale (1963) two-good exchange economy, Walrasian dynamics push disequilibrium prices of the nonnumeraire good away from an equitable (but unstable) interior competitive equilibrium toward infinity or zero. Disequilibrium price paths eventually induce agents on one side of the market to give goods away for free, along with all gains from trade, within one of a pair of corner equilibrium sets. Here, as in Thomas Balogh and Paul Streeten's (1951, p. 75) memorable phrase, "the invisible hand does its work by strangulation." Remarkably, which side of the market gives away its goods depends not on structural parameters of the economy but purely on the market's initial price and the dynamic path this price initiates. Powerful income effects generate positive excess demand (and upward price trajectories) at initial prices above the interior competitive equilibrium and negative excess demand (and downward trajectories) below.

Gale's economy provides an important stress test of the Walrasian hypothesis for two reasons. First, the extreme Walrasian predictions for this economy are intuitively implausible and have perplexed economists for decades, 5 whereas interior

\footnotetext{
${ }^{1}$ This is a fact general equilibrium theorists sometimes lament (see, for example, Alan P. Kirman 1989).

${ }^{2}$ Marshallian dynamics, where quantities adjust given differences between buyer and seller prices, have been found to be more successful in economies with negative externalities (see Plott and Glen George 1992), positive externalities, (Plott and Jared Smith 1999), and recently in an economy with continuous probabilistic market entry (Michael Alton and Plott 2007).

${ }^{3}$ Although modern theorists frequently motivate tatonnement by describing a fictional centralized mechanism, Walras himself did not use such a mechanism to motivate his theory. In fact, Walras conceived of tatonnement as a theory regarding the process governing decentralized markets (see Donald A. Walker 1996). Thus, Walras would likely have been less surprised than modern observers to learn that tatonnement does a good job of anticipating the behavior of decentralized laboratory markets. We thank Omar Al-Ubaydli for pointing this out to us.

${ }^{4}$ Gale's example can be viewed as the limiting case of several well-known $2 \times 2$ economies with three competitive equilibria, the earliest due to Alfred Marshall (1879). It is Marshall's economy to which Balogh and Streeten refer.

${ }^{5}$ Kenneth J. Arrow and Gerard Debreu (1954, p. 269) assume that "impossible combinations of commodities, such as ... the consumption of a bundle of commodities insufficient to maintain life, are regarded as excluded" from the feasible set of consumption bundles. John S. Chipman (1965, p. 730) infers from this passage that, "From this
} 
equilibration and global instability are two highly appealing alternative hypotheses. Indeed, the economy is often used as a reductio ad absurdum, a cautionary tale concerning the limits of aprioristic reasoning about markets. Chipman (1965) writes of the Gale example, "It is best to consider it as a sobering reminder that the pure theory admits of many strange possibilities that cannot be ruled out by a priori reasoning." It is precisely the fact the Gale example is transparently "strange" (Chipman 1965), "queer" (Gale 1963), and implausible that makes it a limiting robustness test for Walrasian dynamics.

Second, the Gale example (unlike the similarly famous and previously studied three-good example of Herbert E. Scarf 1960) is a two-good economy that can be easily implemented in a single commodity double auction with an equal number of net buyers and net sellers. Price dynamics and their implications for each side of the market are utterly transparent, as participants need only pay attention to one price series to quickly understand the character of dynamics. One side of the market has both sufficient information and powerful incentives to resist Walrasian price trajectories.

This project began as a friendly debate among coauthors concerning the robustness of Anderson et al. (2004), which identified price cycles across periods in a laboratory implementation of Scarf's example. A reasonable inference from this research is that, where they conflict, Walrasian dynamics are more important predictors of outcomes than the fixed points that lie at the heart of equilibrium economics. Two authors conjectured that given enough experience (here 13 or more trading periods per session, nearly double the number observed in Anderson et al.), large enough markets (10 subjects of each type, double the number per type in Anderson et al.), transparent enough dynamics (subjects can track dynamic trajectories by looking at only one price), and contemptible enough outcomes (in the Gale economy, half of the subjects' earnings are devastated by dynamic trajectories), Walrasian dynamics would fail and criteria other than tatonnement would come to govern behavior. In particular, the two skeptics conjectured that resistance to tatonnement dynamics by the disadvantaged side of the market would lead the economy to settle in a neighborhood of the equitable equilibrium, or produce signs of global instability instead of the clear trajectories of tatonnement.

The skeptical authors were proved wrong. We report robust evidence that prices in laboratory Gale economies resist the interior competitive equilibrium and march upward or downward toward the corner equilibria. In fact, prices became as high or as low as one could expect given the discreteness of the space of goods in the lab economy so that subjects on the "wrong" side of the market were left trading their entire allotment of goods for a few pennies. We also discover that dynamics, once seeded, are sticky and difficult to reverse.

A handful of earlier studies have shown emergent prices in partial equilibrium environments that disadvantage one side of the market (e.g., Vernon L. Smith 1965). What makes the Gale example curious is that the side of the market disadvantaged is not selected by structural features of the economy such as the number of traders,

point of view, [the Gale corner solutions] do not qualify as equilibrium solutions, and the example becomes one of global instability," before wryly observing, "It would certainly come as news to the inhabitants of many a poor country to learn that starvation had now become 'impossible."” 
or the basic character of supply and demand. Rather, the losing side is driven by something as seemingly arbitrary as the economy's initial trading prices and the dynamics these initial prices set off. It is the inherently dynamic cause of extreme inequity and the existence of a reasonable alternative that makes the example so counterintuitive and the laboratory evidence supporting it compelling.

The remainder of the paper is organized as follows. In Section I we review Walras's theory of tatonnement, introduce our parameterization of a Gale economy, describe our experimental design, and lay out our primary experimental questions. In Section II we present results from our experiment. We conclude with a discussion of our results in Section III.

\section{The Gale Example: Theory and Experimental Design}

\section{A. Walrasian Dynamics and the Gale Example}

Tatonnement is the earliest and best known of the classical theories of market price dynamics. The process begins with an arbitrary vector of initial prices that induce a corresponding vector of excess demands. If a good is in excess demand, its price increases, while its price decreases if the good is in excess supply. This process is iterated indefinitely until excess demand for each good is zero and a competitive equilibrium is reached. It is only in equilibrium that trades are actually executed and endowments adjusted. Consider an economy with two commodities, $x$ and $y$. Normalizing the price of $y$ to one so that $p_{t}$ is the price of good $x$ at time $t$, tatonnement adjustment in discrete time is given by the following difference equation:

$$
p_{t+1}-p_{t}=f\left(Z_{x}\left(p_{t}\right)\right)
$$

where $Z_{x}\left(p_{t}\right)$ is the excess demand for good $x$ given $p_{t}$, and $f$ is a sign preserving function of excess demand. A finite price $p^{*}>0$ is a competitive equilibrium price if $Z_{x}\left(p^{*}\right)=0$. A competitive equilibrium price is locally stable if there exists $\varepsilon>0$ such that for all $\delta \neq 0$ where $|\delta|<\varepsilon, \delta Z_{x}\left(p^{*}+\delta\right)<0$. A competitive equilibrium price is globally stable if $\delta Z_{x}\left(p^{*}+\delta\right)<0$ for all finite $\delta$. Local and global instability are defined similarly, but the $\delta z(\cdot)$ conditions have opposite sign.

We consider the variation on Gale's (1963) economy represented by the Edgeworth box in panel A of Figure 1. The origin of agent 1's coordinate axis is the lower-left corner of the Edgeworth box, while agent 2's origin is the upper-right corner. Agent $i$ has Leontief preferences

$$
U_{i}\left(x_{i}, y_{i}\right)=\min \left\{a_{i} x_{i}, y_{i}+b_{i}\right\}
$$

The ray $y=a_{i} x-b_{i}, x, y>0$, depicted in the Edgeworth box by the black line segment for agent 1 and the gray line segment for agent 2 , is called the expansion

\footnotetext{
${ }^{6}$ Scarf (1960) provided a three-agent, three-good economy with a unique competitive equilibrium that is globally unstable under the basic tatonnement adjustment procedure; tatonnement prices converge to a limit cycle about the competitive equilibrium. Anderson et al. (2004) report that mean prices across periods track this limit cycle in a laboratory implementation of Scarf's example.
} 
Panel A

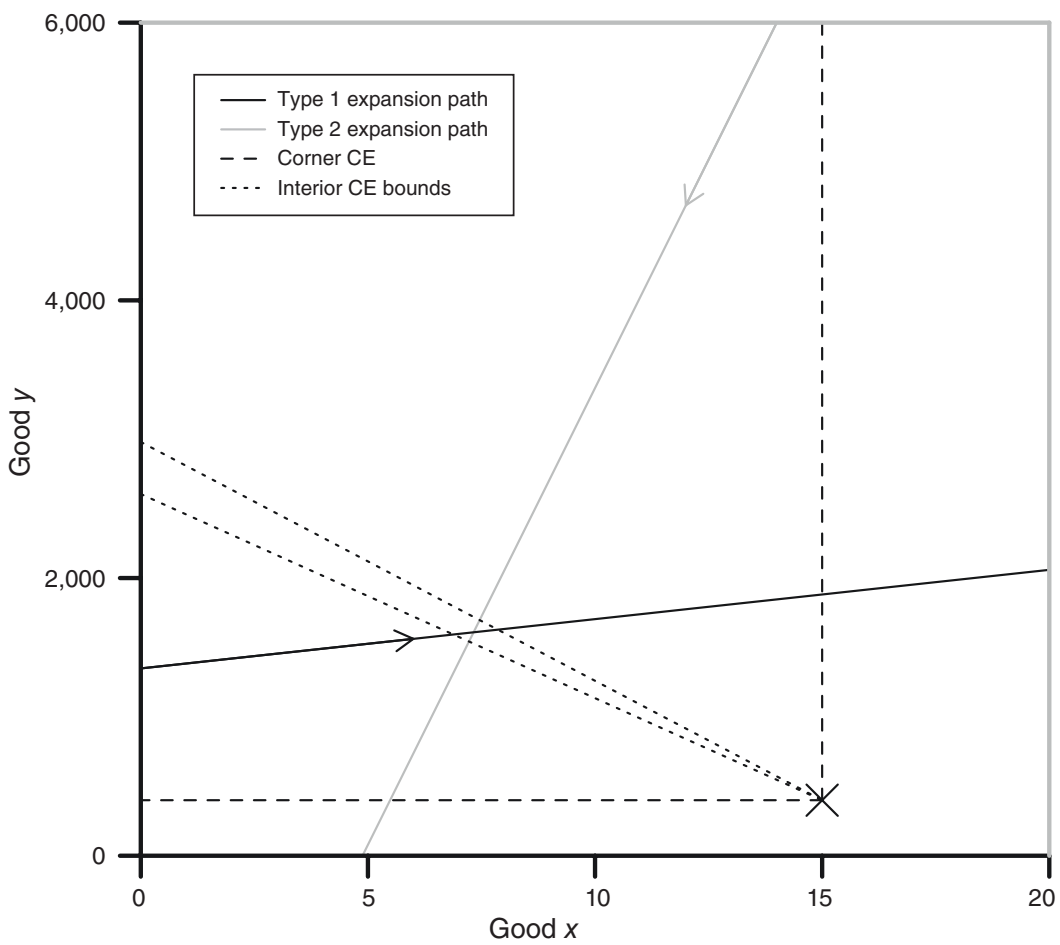

Panel B

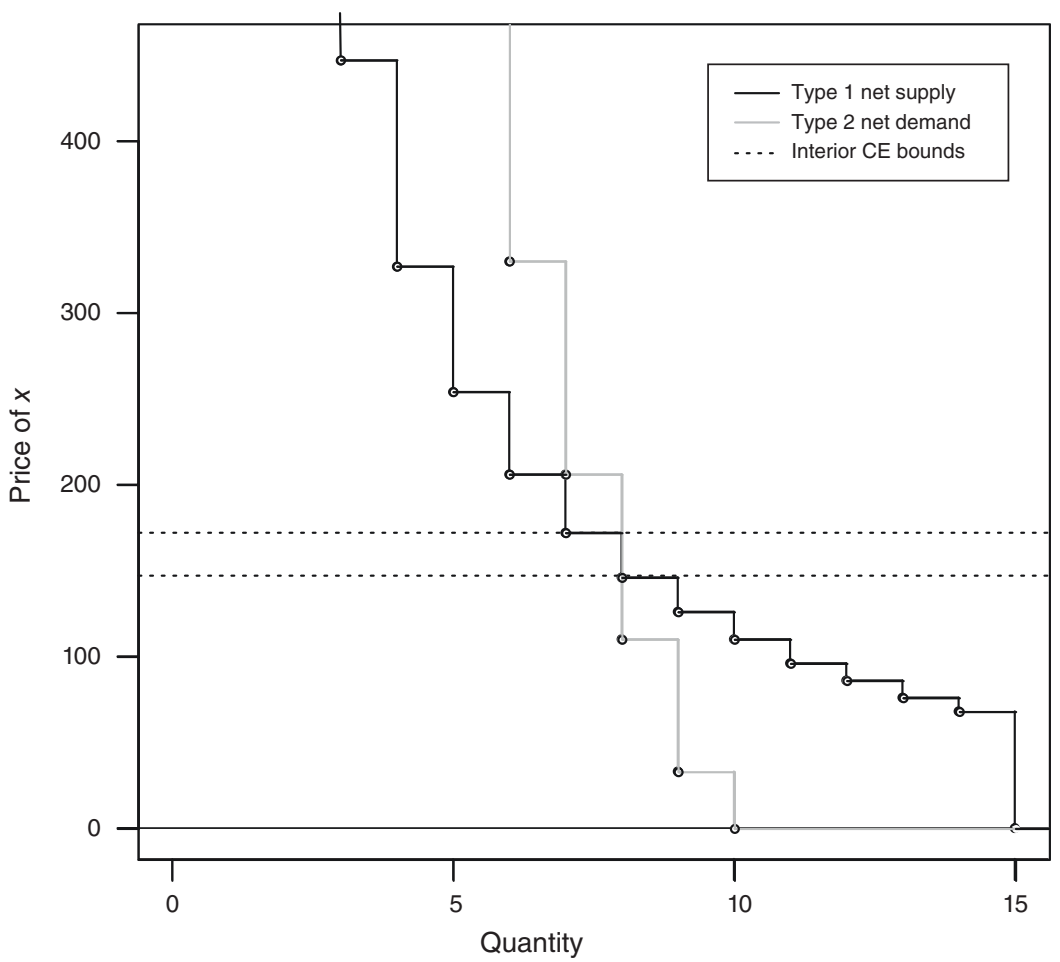

Figure 1. Edgeworth Box (A) and Net Supply and Demand Functions (B) 
path (a generalization of the offer curve) for agent $i$. It represents the set of positive consumption bundles at which the entire quantity of each good contributes to $i$ 's utility (i.e., there are no wasted goods in bundles on this path).

Given endowment $\left(w_{i}^{x}, w_{i}^{y}\right)$, agent $i$ 's (interior) demand is determined by the intersection of her budget line at the prevailing price and the expansion path. It is straightforward to show that the demand functions are given by

$$
x_{i}^{*}(p)=\frac{p w_{i}^{x}+w_{i}^{y}+b_{i}}{a_{i}+p} \text { and } y_{i}^{*}(p)=\frac{a_{i}\left(p w_{i}^{x}+w_{i}^{y}\right)-p b_{i}}{a_{i}+p},
$$

and the excess demand for good $x$ in the economy is

$$
Z_{x}(p)=\frac{m_{1}}{a_{1}+p}+\frac{m_{2}}{a_{2}+p}, \text { where } m_{i}=w_{i}^{y}+b_{i}-a_{i} w_{i}^{x} .
$$

Provided an interior competitive equilibrium exists, its associated price is

$$
p^{*}=-\frac{a_{1} m_{2}+a_{2} m_{1}}{m_{1}+m_{2}}
$$

In Appendix A we derive these functions and show that the interior equilibrium is unstable if and only if $m_{1}+m_{2}>0$.

In Figure 1 and our experiment we set $a_{1}=35.5, b_{1}=-1,349, a_{2}=658$, and $b_{2}=3,947,7$ with endowments $\left(w_{1}^{x}, w_{1}^{y}\right)=(15,400)$ and $\left(w_{2}^{x}, w_{2}^{y}\right)=(5$, 5600). These parameters generate an interior competitive equilibrium (ICE) price $p^{*} \approx 158$. Our laboratory implementation is discrete so the ICE is actually a cone $p \in[147,172]$ emanating from the endowment allocation and centered on the confluence of the expansion paths (this cone is drawn with dotted lines in the Edgeworth box in panel A of Figure 1). Panel B of Figure 1 provides another view of the discretized economy, plotting net supply and demand functions of good $x$ with respect to the endowment. Net supply and demand are equal within the ICE bounds, resulting in zero excess demand in the competitive price tunnel.

The ICE is interior, equitable (each party receives identical payoffs and gains from trade under our payoff scaling), and is defined by an excess demand of zero. It is globally unstable, however, under tatonnement. At prices higher than (clockwise from) the ICE price, agent 2's demand for good $x$ exceeds agent 1's supply, generating positive excess demand and, by (1), causing prices to rise away from the ICE. At prices lower than (counter clockwise from) the ICE price the reverse is true and, by (1), prices will fall away from the ICE.

Walrasian dynamics drive adjustment until prices reach either zero or infinity ${ }^{8}$ and can no longer adjust in the direction of excess demand. These prices are, by

\footnotetext{
${ }^{7}$ These are approximate; precise values are given in Appendix Section A.

${ }^{8}$ In our discrete implementation of this economy, $p \geq 2,800$ actually induces a stable "near corner" equilibrium where one unit of good $x$ is exchanged.
} 


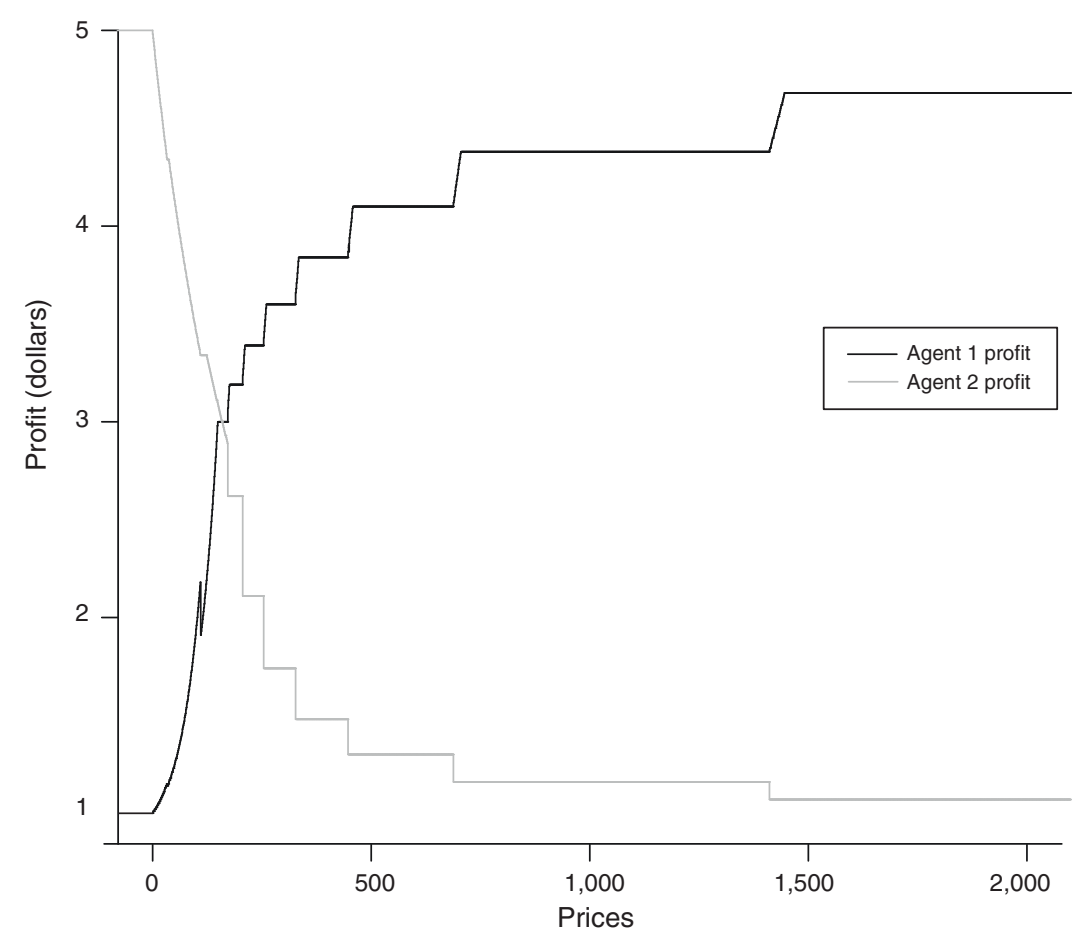

Figure 2. Total Predicted Earnings of Both Sides of the Market as a Function of Price

convention, competitive equilibrium prices, though of an odd form since excess demands are far from zero. These corner prices generate a range of allocations (we call them corner competitive equilibria, or CCE) that are (weakly) optimal but highly inequitable. In either CCE, one agent gives away some amount of a commodity to the other for free, along with all of the gains from trade. Which CCE is selected and which side of the market is disadvantaged in equilibrium depends entirely upon initial prices and the dynamics they ignite. ${ }^{9}$

\section{B. Experimental Design and Procedures}

In order to assess the empirical content of the extreme tatonnement predictions in Gale's economy, we examined a series of discrete-good laboratory markets parameterized as above. In each of 8 sessions, $\underline{10}$ between 12 and 20 subjects traded for approximately 3 hours. In each session, half of the subjects were assigned agent 1's preferences and endowments and half agent 2's, forming a replica of the economy described above.

\footnotetext{
${ }^{9}$ In Appendix Section A we show how Gale's example is simply the limiting case of constant elasticity of substitution (CES) preferences with a utility bias for "home production" (that is, agents have a stronger relative preference for the good in which they are endowed in greater proportion to total resources). Thus, there is a family of smooth economies qualitatively similar to Gale's example but where the "outer" equilibrium prices are strictly interior. By switching endowments (thus removing the utility bias for home production), such a CES economy becomes globally stable with a unique ICE. Gjerstad (2007) implements globally stable 2x2 CES economies in the lab and observes reliable convergence to the ICE.

${ }^{10}$ There was also a pilot session using different utility parameters.
} 
Sessions were divided into a sequence of 13-15 trading periods each lasting 6-15 minutes. Period lengths within each session started high and were gradually decreased as subjects became more comfortable with the trading environment. 11 Trade was conducted via computerized continuous double auction using MarketScape software, and traders bought and sold units of $x$ using the numeraire $y$ as the medium of exchange. Subjects tracked their potential earnings using a special graphical program implemented in Excel that allowed them to visualize their induced indifference curves and expansion paths and quickly calculate the payoff consequences of prospective trades. Screenshots of these programs are presented and discussed in online Appendix C.

As with most market experiments, implementation was via stationary repetition. At the end of each period subjects earned cash payments (paid at the end of the session) based on their ending allocations, and induced utility functions and allocations were returned to endowment levels for the next period of trade. Stationary repetition is especially useful in our study because tatonnement dynamics assume price adjustments at a fixed endowment. By resetting endowments at the beginning of each period, we can neatly map Walrasian predictions onto the sequence of period average prices.

The session design is summarized in Table 1. Each session opened with a block of periods we call the primary phase. In half of the sessions we allowed primary phase prices to initiate freely. We call these primary-free sessions. In the other half we controlled the sign of initial excess demand using price controls; we call these primarycontrol sessions. Following the primary phase we attempted to reverse observed price dynamics by switching the sign of the market's excess demand using price controls. We refer to this later block of periods as the reversal phase. The period in which we began the reversal phase was triggered by a determination of price convergence. In several sessions, time permitting, we lifted price controls in the final period of the reversal phase. In the price control columns of Table 1, we specify what types of price controls were implemented and in which periods. So, for example, in the primary phase of session 6 a price floor above the ICE was imposed during periods $1-7$ and was lifted during periods 8 and 9 . During the reversal phase, a price ceiling below the ICE was imposed during periods 10-14 and lifted in period 15.

Subjects received extensive training and instruction prior to trading. Instructions concerning both the character of preferences and the details of the MarketScape interface were distributed and read aloud to subjects; these instructions are included in online Appendix C. After reading instructions, subjects engaged in a period of paid trade at a fixed price, allowing them to learn how to calculate earnings and submit orders without being allowed to engage in the strategy of setting prices. This gave them experience with their induced preferences and with the mechanics of the double auction. 12

\footnotetext{
${ }^{11}$ Specifically, there was a paid training period of 15 minutes at prespecified prices. The first "real" period was 15 minutes long, the second 12 minutes, the third 10 minutes, the fourth 8 minutes, and the rest 6 minutes.

${ }^{12}$ We varied the training period price from session to session; this price was 120 in session 1,90 in sessions $2-4$, and 275 in sessions 5-8. Thus, half of the training prices were initiated in a region of negative excess demand, the other half in a region of positive excess demand. While the training price may potentially influence the initial prices in period 1, our objective is to study the evolution of prices over time, wherever they happen to start; disequilibrium theory is generally silent on where initial prices come from. In fact, the sign of excess demand at training prices was a poor predictor of the sign of excess demand at subsequent period 1 prices, as two of four primary-free sessions immediately exited the signed region of excess demand in which they were trained.
} 
Table 1-Summary of Session Design

\begin{tabular}{lcccccc}
\hline \hline & & \multicolumn{2}{c}{ Primary phase } & & \multicolumn{2}{c}{ Reversal phase } \\
\cline { 3 - 4 } Session & Market size & Price control & Free prices & & Price control & Free prices \\
\hline 1 & 12 & & $1-14$ & & & \\
2 & 20 & & $1-9$ & & Ceiling: $10-12$ & 13 \\
3 & 20 & Ceiling: $1-4$ & $5-8$ & & Floor: $9-14$ & \\
4 & 20 & Ceiling: $1-11$ & 12 & & Ceiling: $13-14$ & \\
5 & 20 & Floor: $1-8$ & 9 & & Ceiling: $10-14$ & \\
6 & 20 & Floor: $1-7$ & $8-9$ & & Ceiling: $10-14$ & 15 \\
7 & 20 & & $1-5$ & & Ceiling: $6-14$ & 15 \\
8 & 16 & & $1-4$ & & Ceiling: $5-13$ & \\
\hline
\end{tabular}

We chose parameters to achieve several goals. First, to allow only discrete trades while maintaining a sufficiently fine price grid, the numeraire good $y$ is scaled to a much larger number of units than the commodity good $x-$ a conventional normalization of the Edgeworth box in general equilibrium experiments. We also included an additive constant in the induced utility function (not in Gale's original economy) that allows us to keep the volume of orders reasonably low while maintaining a relatively narrow ICE price tunnel. Economies with lower trading volumes take less time to clear than economies with higher volumes, allowing us to run shorter (and thus more) periods.

We adopted a nonlinear, monotone-increasing exchange rate from induced utils (that is, $U_{i}\left(x_{i}, y_{i}\right)$ in (2)) to dollars in order to equalize total payoffs at all three equilibria and create symmetry in relative inequality at the two corner equilibria. The map from price to profit is shown in Figure 2. At the ICE price of 158 (and corresponding ICE allocation), subjects of both types earn $\$ 3$ per period. At her "good" ("bad") corner equilibrium a subject of either type earns $\$ 5$ (\$1). As is clear from Figure 2, there is a rough symmetry between the two subject types with respect to the marginal impact of price changes on profits, so that any price change is an approximately zero sum transfer from one subject type to the other. If our util-todollar exchange rate had instead been linear and, for example, we had normalized the ICE and "bad" CCE payments to be $\$ 3$ and $\$ 1$ per period, respectively, then the $p=0$ CCE payment for type 2 agents (their "good" equilibrium) would equal only $\$ 3.57$. Thus, incentives for these subjects would have been low relative to type 1 subjects for prices below the ICE range (the same holds true for type 1 agents in the high-price CCE).

\section{Experimental Questions}

Our design permits investigation of four main questions. The first is whether the interior competitive equilibrium range is behaviorally stable. When prices are in the ICE, do they stay there? Do prices outside of the ICE move toward the ICE over time? The former is a measure zero event in the continuous economy if the initial price is drawn from a continuous distribution, but of practical interest in our discrete implementation. The latter seeks to identify expressly anti-tatonnement dynamics, where prices move opposite the sign of excess demand.

Question 1: Is the interior CE behaviorally stable? 

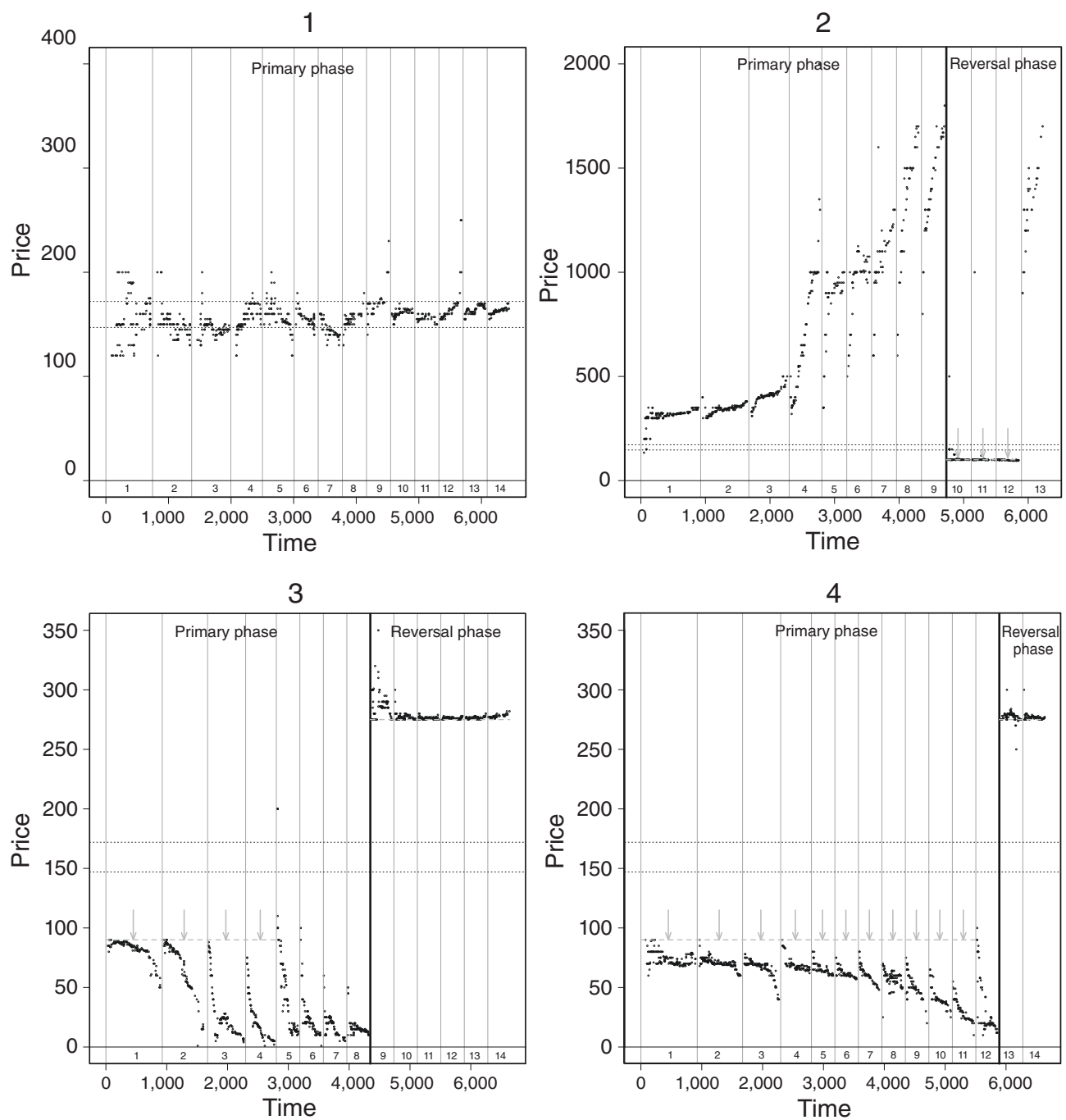

Figure 3. Price Series from Sessions $1-4$

Notes: Vertical lines demarcate periods and horizontal dotted lines show ICE bounds. Arrows ending in horizontal gray dashed lines designate price controls.

If the ICE is unstable in the sense that prices are not drawn to it, it is still possible that prices show signs of global instability by failing to follow a clear trajectory. Our second question is, therefore, whether there is a strong (and direct) correspondence between the sign of excess demand and the direction of period-to-period price adjustments as tatonnement predicts.

Question 2: Are price dynamics Walrasian?

Even if prices move in a relatively orderly fashion toward the corner competitive equilibria, it is possible they could stabilize in a neighborhood "far" from CCE prices. It is the prediction of corner convergence that seems most implausible ex 
ante; thus, our third question is whether this implausible prediction bears out in the data.

Question 3: Do prices reach corner equilibria and are these equilibria behaviorally stable?

We answer the preceding three questions using the primary phase data. Our final question is whether we can actually reverse the trajectory of prices by exogenously changing excess demand. An alternative hypothesis is that primary dynamics, once established, are sticky.

Question 4: Can primary phase price dynamics be reversed?

\section{Results}

\section{A. Primary Dynamics}

Figures 3 and 4 display transaction prices from each session of the experiment. Periods are separated by vertical gray lines, phases by vertical black lines, and the ICE bounds are demarcated by horizontal dotted lines. Dashed lines at the end of arrows represent price controls (downward arrows are price ceilings, upward arrows price floors). We focus on the primary phase dynamics and later consider the reversal phase.

In session 1, early first period transactions are within or very near the ICE bounds, and prices stay centered there for the remainder of the session. In every other session, prices begin outside the ICE and never enter its bounds (one early transaction in session 2 notwithstanding). Indeed, as we'll confirm below, Primary prices always trend away from the ICE from period to period. When prices initiate above the ICE, they explode to an order of magnitude above it; when they initiate below, prices collapse to nearly (and sometimes exactly) zero. Prices within period also show a systematic tendency away from the ICE. These tendencies match Walrasian predictions as prices above the ICE generate positive excess demand and prices below negative excess demand. These observations answer our first question and provide us with our first result.

RESULT 1: The interior competitive equilibrium is behaviorally unstable. When prices initiate inside the ICE they stay there. When they initiate outside the ICE they show no systematic tendencies toward it over time.

Free session excess demand is endogenous, making it difficult to be sure it is causally related to price movements. Prices that initiate at positive excess demand also initiate high; perhaps the climbing prices we observe in free sessions reflect a dynamic tendency that codetermines initial price and the price gradient. It is possible that excess demand is not in fact causally related to excess demand.

To better identify the relationship between excess demand and price, we exogenously controlled and varied initial excess demand in half of our sessions 
5

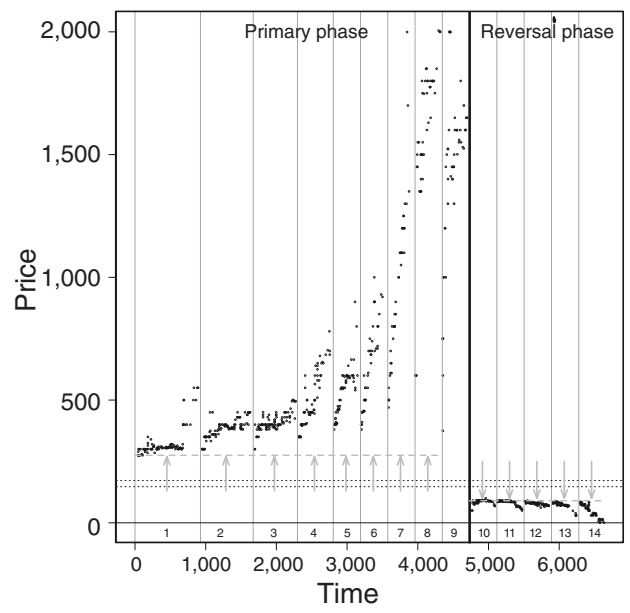

7

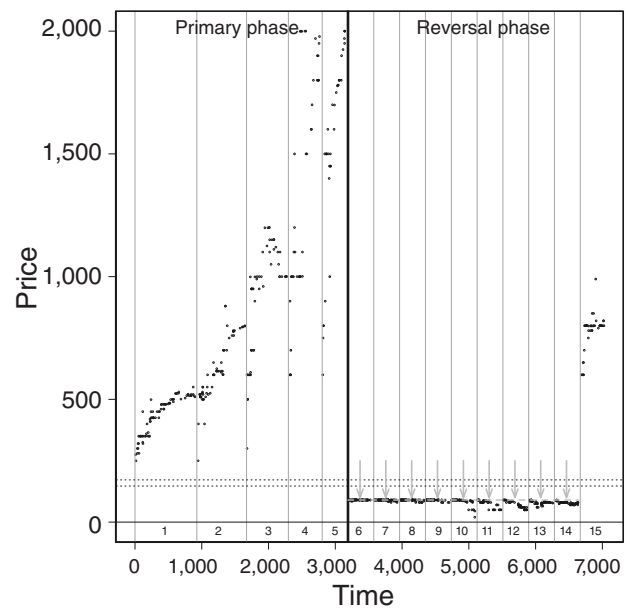

6

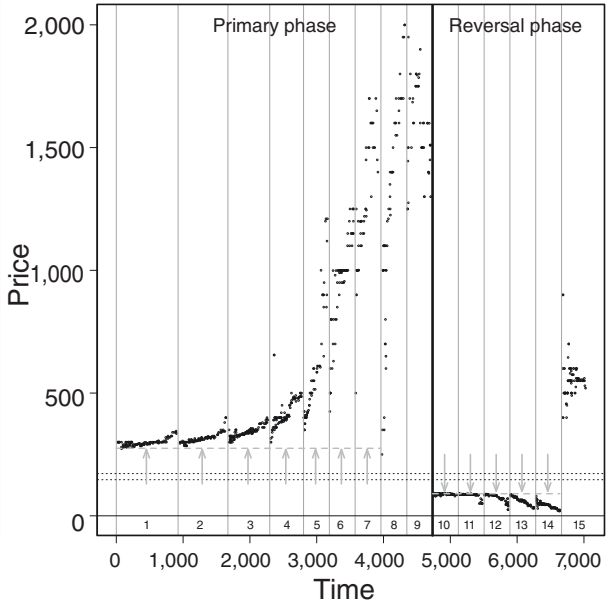

8

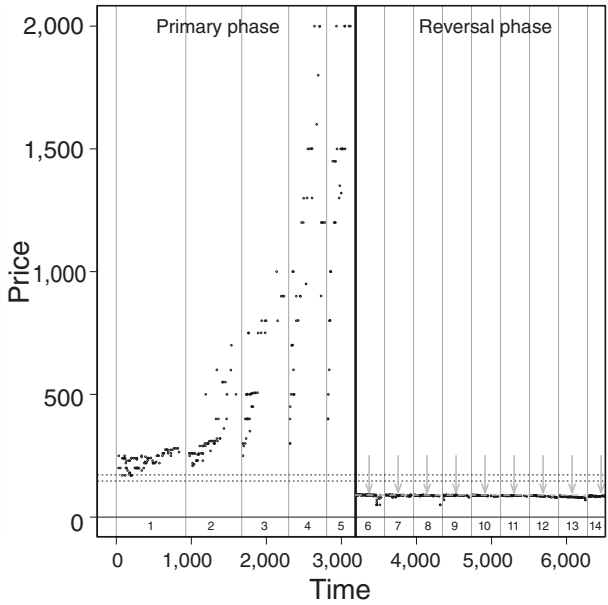

Figure 4. Prices from Sessions 5-8

Notes: Vertical lines demarcate periods and horizontal dotted lines show ICE bounds. Arrows ending in horizontal gray dashed lines designate price controls.

(sessions 3, 4, 5, and 6) ${ }^{13}$ In sessions 5 and 6 we used price floors in the first few periods to force excess demand at initial prices to be positive. In sessions 3 and 4 we forced prices to initiate with negative excess demand using price ceilings. Dynamics in these sessions are also Walrasian; sessions with price ceilings below the CE have prices dropping toward zero, while sessions with price floors above the CE have prices that rise far above the ICE bounds. Moreover, in each of these sessions we lifted price controls, and prices continued both between and within period on their

\footnotetext{
${ }^{13}$ Several previous experiments employ price controls to influence the sign of excess demand (e.g., Plott and George 1992; Plott 2000). To our knowledge, however, Omar Al-Ubaydli , John A. List, and Michael K. Price (2010) are the first to point out and seriously consider identification issues associated with experimental price dynamics. While we use price controls to overcome endogeneity, they employ a clever and considerably subtler instrument in a series of partial equilibrium markets.
} 
original trajectories, sometimes after a brief but unsuccessful surge in the opposite direction. ${ }^{14}$ Via exogenous treatment variation we are able to infer that dynamics are, in fact, caused by excess demand.

To test the Walrasian hypothesis more formally we calculate, for each session, the Mann-Kendall $\tau \in[-1,1]$, an ordinal, nonparametric measure of trend, for weighted average price across periods. ${ }^{15}$ In sessions in which initial weighted average prices are at positive excess demand $\tau$ is nearly 1 , indicating strong positive price trend, while in sessions with negative excess demand, $\tau$ is close to -1 . These measures are significantly different from zero at the 5 percent level in sessions 2-7. In session $8, \tau$ is very close to $1(0.999)$, but the small number of primary periods allows us confidence at only the 10 percent level. These statistics generate our second result.

RESULT 2: Primary disequilibrium price dynamics are Walrasian. From period to period, prices move significantly in the direction of the sign of excess demand.

Within period, endowments adjust at each transaction price in the double auction so theoretical models of price dynamics within periods are difficult at best. For example, tatonnement models typically assume stationary endowments. Nonetheless, in Figures 3 and 4 the trend in prices within period is obvious: under positive excess demand, prices virtually always rise within period, and under negative excess demand they nearly always fall.

To check this more formally, we calculate the Mann-Kendall $\tau$ for prices and time within period for each disequilibrium period in the primary phase. In all primary phase periods but one (period 9 of session 6) we observe significant trend within period.

In these periods with significant trend, prices universally match excess demand at both the current and previous average price. We document this as a further result.

RESULT 3: The sign of disequilibrium price movements within period matches the sign of excess demand.

Although there is clear evidence that tatonnement gets the sign right, there is little evidence in our data of a relationship between the magnitude (of the absolute value) of excess demand and the size of price changes. $\frac{16}{}$ This reflects the challenge to theory presented by Gale economies with parameters such as ours. Excess demand (or supply) increases as the economy moves toward corner equilibria. As the economy approaches equilibrium, however, incentives to trade begin to evaporate. These slowdowns could have the effect of dampening price changes at high excess demand

\footnotetext{
${ }^{14}$ In fact, these brief surges provide particularly strong tests of Walrasian dynamics "near" the CCE; the lifting of the price control is used by some subjects as a device to coordinate on antitatonnement pricing. These resistance attempts universally fail and end up being very short-lived, as they are quickly overpowered by Walrasian forces.

${ }^{15}$ Similar results obtain using cardinal correlation measures such as Pearson's $\rho$. In online Appendix B we report parametric tests of price dynamics, both within and between period, using standard panel data techniques, and find similar results.

${ }^{16} \mathrm{An}$ econometric analysis of the relationship between excess demand and price movements between periods is provided in online Appendix B. See also Hirota et al. (2005) for similar findings in laboratory Scarf economies. They do find quantitative relationships but the dynamics become complicated by the multiple market setting they study.
} 
(or supply) and may make it difficult to observe any latent magnitude effects. It seems that the very features of the Gale example that generate its extreme predictions also make it a challenging arena for understanding the structural relationship between price changes and excess demand.17

\section{B. Convergence and Reversal}

Disequilibrium prices show a strong tendency away from the interior equilibrium and toward the corner equilibria. How close to the corner equilibria do our markets come?

Our restriction of trade to the integer grid actually implies finite $p \geq 2,800$ are competitive equilibrium prices, where each type 2 (1) subject buys (sells) one unit of $x$. In such equilibria the payoff to each type 2 (1) subject is $\$ 1.07$ (\$4.68); recall that subjects earn $\$ 1$ each at their endowments, so type 2 subjects are very nearly supplying good $y$ for free. Thus prices of $p \geq 2,800$ would certainly suggest "corner" prices.

But consider optimal symmetric (by type) trade at a price less than 2,800 but still "large." For $p \geq 1,446$ the profit of each type 1 subject is $\$ 4.68$, the same as in the (discrete) "corner" equilibrium (see Figure 3). Therefore, there should be no pressure from the supply side for prices to go any higher. At $p=1,446$, however, the type 1 subjects supply one unit of $x$ each while the type 2 subjects demand three units, so there is substantial excess demand.

How salient is this excess demand? When $p=1,446$, if the demand of a type 2 subject were fulfilled she would earn $\$ 1.28$, but under optimal symmetric trade (so that she is able to acquire only 1 unit of $x$ ) she earns $\$ 1.07$. Therefore, the excess demand is worth $\$ 0.21$. Since symmetric optimal profits are constant for $p \geq 1,446$ and excess demand is worth a fairly small amount $(\$ 2-\$ 3$ over the course of an entire session), $p=1,446$ seems like a natural benchmark for convergence to a near-corner price (and 7 cents a benchmark corner trading profit for a price-disadvantaged subject). It is worth noting that the "demanded" profit for type 2 subjects shrinks steadily as prices increase in the interval $p \in[1446,1643]$, above which a type 2 subject demands profit of $\$ 1.16$ for all $p \in[1,643,2,494]$ (so excess demand is worth only $\$ 0.09$ in this interval) before again declining toward $\$ 1.07$. Given this wide band (in prices) of profit nonmonotonicity with such small "lost" profit attached to excess demand, $p \geq 1,643$ is practically an equilibrium price.

By comparison, the payoff gradient on the price path to the $p=0$ equilibrium is relatively smooth. For symmetry we consider the lower-near-corner range to be any price that yields trading profit of 7 cents or less to the type 1 subjects; this is true at any $p \leq 19$.

Figure 5 plots end-of-period prices (weighted average transaction price during the final minute of the period) for each session-phase combination. For visibility across vastly different scales, the data are divided into a panel for periods initiating

\footnotetext{
${ }^{17}$ Gjerstad (2007) studies a laboratory economy that does not have this feature of the Gale economy and thus manages to get a clear picture of the parameters in that environment. He estimates parameters governing both tatonnement (between period) and Hahn and Negishi (within period) processes and finds strong support for magnitude effects.
} 

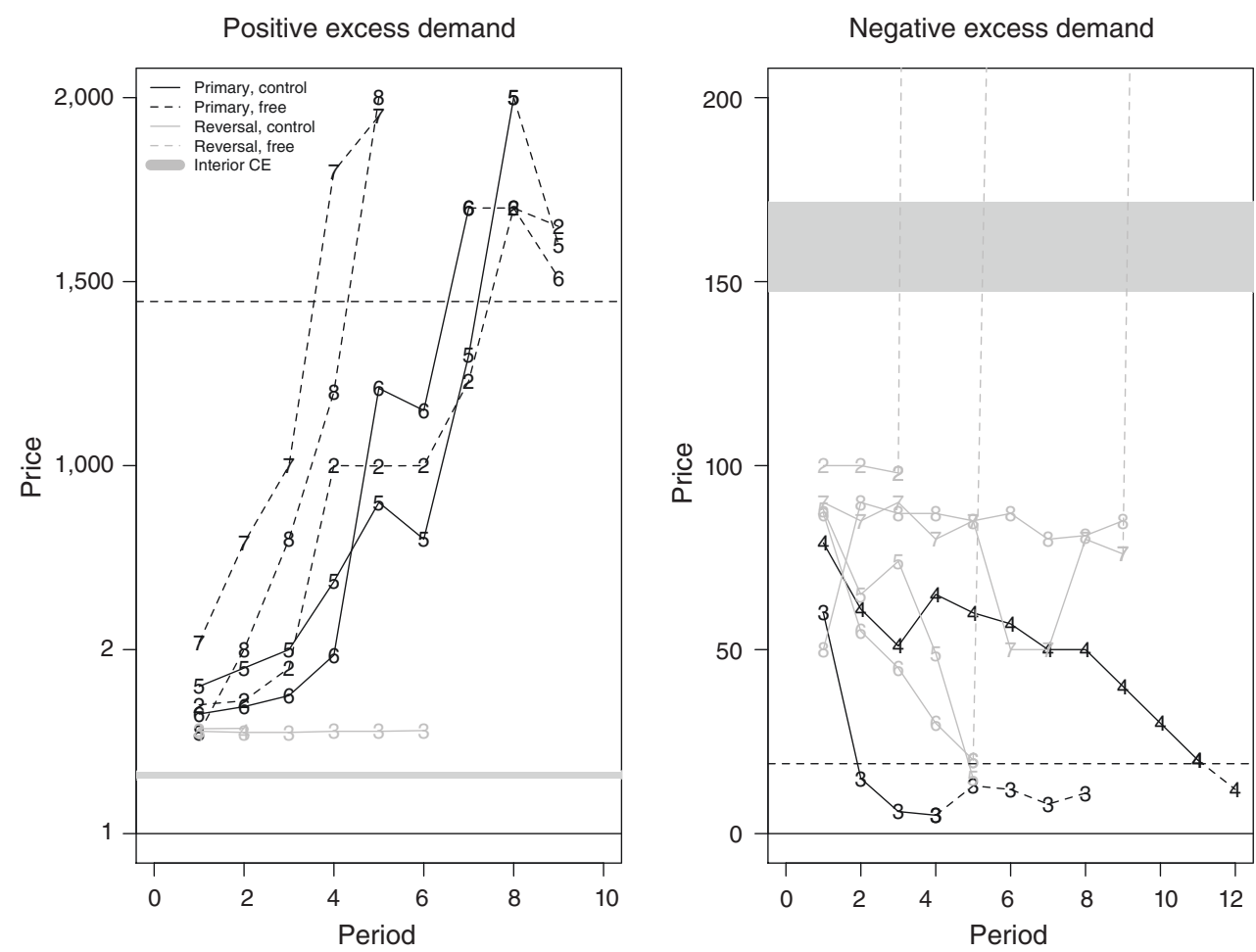

Figure 5. End-of-Period Prices by SEssion

with positive excess demand and a separate panel for periods initiating with negative excess demand. Primary dynamics are plotted in black, price control periods are linked by solid lines, while free periods are linked by dotted lines. Horizontal black lines show the bounds for our near-corner prices both on the high and low end. In all seven disequilibrium sessions we observe prices entering this range by the end of the primary phase. Mean prices therefore reach levels extremely close in payoff space to CCE prices.

RESULT 4: Prices converge to close neighborhoods of corner competitive equilibrium prices.

It is important to consider measures of corner equilibration other than price convergence. Convergent prices are useful, but unavoidably conceal heterogeneity inherent in the double auction institution that particularly matters in general equilibrium settings. Double auction markets are cleared, not at a single price within period, but at a host of prices evolving over the period's duration. Moreover, subjects need not submit optimal demands at each transaction price. Indeed, it is typical to observe individual subjects making multiple trades at multiple prices over the course of a single period.

We can sidestep these problems by directly studying the final allocations achieved by the market; how "close" are these allocations to corner equilibrium allocations? 
A simple metric of linear distance in the Edgeworth box is of limited value because of the highly nonlinear nature of rewards in this space, because there is a large set of equilibrium allocations from which to benchmark distance, and because allocations are restricted to a discrete grid (meaning both that a range of prices typically supports identical levels of demand and supply and that a single price tick can imply a discrete jump in excess demand). An appealing alternative is to examine inequality across player types in the achieved gains from trade (relative to the endowment), a one-dimensional measure that is increasing as allocations move from the ICE toward either CCE $\stackrel{18}{ }$ This measure is also a particularly strong test of corner convergence in that it measures the aspect of the corner equilibria that seemed least plausible, ex ante.

For each period, we calculate the share of total gains from trade achieved by the type 1 side of the market. At the upper corner (for $p \geq 1,446$ ) the benchmark symmetric optimal measure is 0.981 while at the lower corner (for $p=19$ ) it is 0.019 . In Figure 6 we plot these benchmarks as dashed horizontal lines. We also include the symmetric optimal benchmark gains in the ICE in shaded gray.

For each session and period we plot the evolution of type 1's average share of the earnings, with a separate panel for the primary and reversal phases. Primary phase results are compelling. In session 1, where prices initiate and remain in the ICE tunnel, gains from trade are nearly evenly split. In all disequilibrium periods prices move decisively ${ }^{19}$ away from an even split, generally ending with one side of the market earning in excess of 95 percent of the gains from trade. These shares come very close to those obtaining at corner equilibria. 20

RESULT 5: Out-of-equilibrium dynamics lead one side of the market to capture nearly all gains from trade, eventually more than 20 times that of the other side. These divisions are close to those predicted at corner equilibria.

Primary phase data converged quickly, ${ }^{21}$ so in sessions $2-8$ we attempted to reverse the dynamics, using price controls to switch the sign of excess demand. The results of this effort were mixed, and our data, though preliminary, suggest that dynamics are sticky once seeded. In sessions 5 and 6 prices do drop substantially over time in an apparent successful reversal, while in sessions 3,7 , and 8 they consistently hug the price constraint (in 2 and 4 there are too few data to make a call). In three sessions $(2,6$, and 7$)$ we eventually lifted the constraint and in each case prices

\footnotetext{
${ }^{18}$ Note that total gains from trade vary little at optimal or near optimal demands in our parameterization of the Gale economy; the main effect of a change in price on payoffs is in relative shares of the gains from trade earned by each side of the market. Online Appendix B presents plots showing flat total gains from period to period.

${ }^{19}$ In session 3 there is a temporary spike toward equity when price controls are relaxed, but shares quickly plummet back toward zero.

${ }^{20}$ Note that although earnings shares change dramatically over the course of sessions, total realized payoffs hardly change at all. Earnings are, moreover, very close to predicted levels, indicating markets are relatively efficient in that subjects typically extract nearly all of the gains from trade. Details are provided in online Appendix B.

${ }^{21}$ Though in online Appendix B we provide suggestive evidence that prices had generally not yet finished moving by the close of the primary phase and likely would have continued to move away from the ICE had we extended the duration of the primary phase with additional periods.
} 

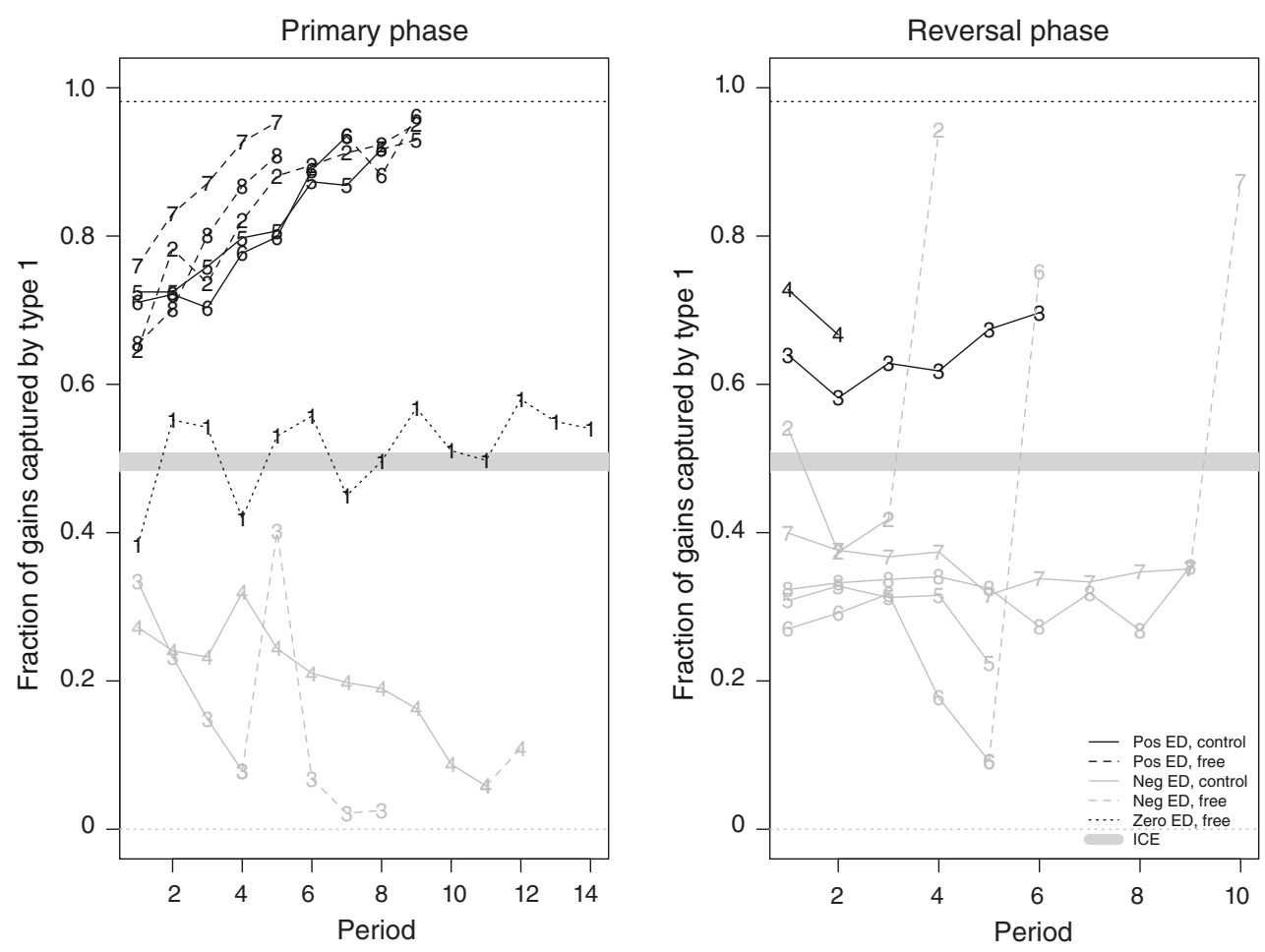

Figure 6. Average Share of Gains from Trade for Type 1 Subjects by Phase, Period Within Phase, and Session

leapt past the ICE, returning to their primary phase trajectories (see the right-hand panel of Figure 5 for a clear view). ${ }^{22}$ We therefore conclude:

RESULT 6: Dynamics once established are typically sticky and difficult to reverse with price controls.

\section{Discussion}

Much of the appeal of experiments lies in their capacity to surprise us. They often do this by providing us with evidence that intuitive theories can fail to predict behavior, but also by showing us that highly counterintuitive theories can succeed in predicting behavior. We have taken one of the more counterintuitive theoretical examples in economics and provided evidence that it precisely anticipates outcomes in laboratory markets. In the process, we have provided new evidence that Walrasianlike dynamics govern price adjustment in general equilibrium environments.

Prices in our markets generally initiate outside of the economy's conventional and equitable competitive equilibrium. When they do, as predicted, prices either explode or collapse to nearly zero, driven by nothing but dynamic forces set off by initial

\footnotetext{
${ }^{22}$ In online Appendix B we discuss the reversal phase in more detail and provide preliminary evidence suggesting that overtrading by the disadvantaged side of the market is a proximate cause of the failure of dynamics to reverse.
} 
prices. These forces continue to exert influence even at extreme prices, resulting eventually in one side of the market giving away its endowment for pennies and the other harvesting nearly all of the gains from exchange.

Although the extremity of the results seemed unlikely ex ante (at least to two of the authors), it comes about for ultimately economically sensible reasons. Indeed, the Walrasian dynamics driving our results are simply a general equilibrium analogue of our standard textbook explanation of equilibration in simple supply and demand markets. Because of the Gale economy's powerful income effects, prices greater than the interior CE induce buyers to demand more units than sellers are willing to supply. Buyers, scrambling to acquire scarce units, bid prices up and, because no fixed point exists to extinguish this process, prices continue moving ever upward. ${ }^{23}$ Symmetric arguments hold when prices begin below the interior equilibrium; low prices cause a glut of supply and drive prices downward in a process that ends only at prices near zero.

Chipman (1965) makes the case that the Gale example "is a special limiting case, and should not be taken too seriously as providing an illustration of any real situation." While strictly speaking we agree, CES preferences can generate economies with multiple equilibria that have qualitatively similar but less extreme dynamics, 24 and we suspect that our basic findings concerning the character of Walrasian dynamics are transferable to these more realistic (and more moderate) settings. Regardless, our interest in the Gale economy derives not from its realism but instead from the particular stress it imposes on Walrasian predictions. It is because nature rarely produces environments this tough that a laboratory test is particularly informative.

The implication of our research is that classical classifications of the stability of equilibria are empirically meaningful, even when markets are not cleared in a tatonnement institution, and even when the implications of stability classifications are quite extreme. We believe our paper, in conjunction with the handful of recent papers on the topic, represents a broad empirical vindication of much classical general equilibrium theorizing on out-of-equilibrium dynamics.

Our paper advances a small prior literature on dynamics in economies with unstable interior equilibria. Anderson et al. (2004) and Hirota et al. (2005) study Scarf's (1963) three-good economy which has a single, theoretically globally unstable interior equilibrium. They report evidence that this economy is indeed globally unstable; prices cycle about the equilibrium, as predicted by Walrasian dynamics, but do not converge to equilibrium during the three hour sessions. Indeed, Hirota et al. (2005) study parameterizations with theoretically divergent cycles and provide evidence that prices, in fact, move modestly away from the interior equilibrium over time. The first to demonstrate that income effects can produce market instability was Plott (2000), who examines two-good economies with downward sloping supply curves for the nonnumeraire good, generating multiple interior (in payoff space) equilibria. He reports evidence that Walrasian stability classifications are good predictors of convergence. 25

\footnotetext{
${ }^{23}$ Of course, in our discrete implementation the incentives to continue driving prices eventually go to zero.

${ }^{24}$ See Chipman (2010) and Appendix Section A for more details.

${ }^{25}$ Plott (2000) reports evidence in some sessions of prices converging to a stable equilibrium with a price of zero. In this price region of Plott's economy, however, the traded commodity is actually an economic "bad" for sellers, who substantially improve their earnings relative to autarky by trading at a zero price (a net gain of
} 
Like Anderson et al. (2004), our economy has a unique and unstable interior equilibrium, though like Plott (2000), a stable alternative equilibrium exists. Unlike both of these strands of work, the Gale example has two symmetric stable alternative equilibria, each deeply inegalitarian relative to the unstable interior alternative. On one hand substantial experimental evidence favoring Walrasian dynamics suggests economies should equilibrate at these inegalitarian corner outcomes. On the other hand, there is a large experimental literature suggesting that, in part because of social preferences, egalitarian distributions tend to be focal, especially in ex ante symmetric environments like ours. This evidence appeals to a compelling intuition that the interior but unstable outcome is more likely to emerge. Because the Gale environment pits Walrasian dynamics so strongly against intuitions (and evidence) regarding individuals' preferences, it poses a considerably more strenuous test of Walrasian dynamics than previous work. Our results highlight in a particularly sharp way the fact that market dynamics are emergent phenomena and the outcomes determined are not direct objects of individual choice. In the words of the eighteenthcentury Scottish philosopher Adam Ferguson (1767), the outcomes are "the result of human action but not ... human design."

Much work remains to be done in this area. A secondary result from our project (and Plott 2000) is that dynamics do not readily or reliably adapt to shocks to excess demand. Further investigation may illuminate the causes of sticky dynamics. As we point out in Section III, the special character of excess demand functions in the Gale example - excess demand increases as the economy approaches equilibriummakes it difficult to estimate the structural relationship between excess demand and price movements. High excess demand should induce faster price movement, but, here, high excess demand also coincides with diminishing marginal utility of consumption, possibly leading to slowdowns as prices approach corner equilibria. Studying less extreme, smooth variations on Marshall's (1879) economy (using CES or quasi-linear preferences) would avoid this complication and might yield a quantitative characterization.

Finally, our experiment is designed to demonstrate the character and test the limits of dynamics. Our units of observations are market cohorts; strong interdependence between subject decisions and endogeneity of key variables limit us from saying much about individual decision making with much confidence. An important unexplored frontier is to use novel designs that exogenize excess demand (perhaps via carefully controlled shocks to endowments or preferences) within period to enable credible characterizations of how individual decision making operates in these markets.

\section{ApPendix: Theoretical BACKGROUnd And Details}

\section{A. Optimality and Stability for Gale's (1963) Example}

As discussed in Section IA, the expansion path for an agent in Gale's economy is given by the equation $y=a x-b$ for $x, y \geq 0$. This ray is the locus of "corners"

$\$ 3$ per period). This stands in stark contrast to Gale's economy, where agents give up all gains from trade as prices converge to zero or infinity. 
of the agent's Leontief indifference curves, restricted to the feasible set. An agent's budget constraint is given by the equation $p w^{x}+w^{y}=p x+y$. An agent's optimal consumption bundle $\left(x^{*}, y^{*}\right)$ is given by the intersection of his expansion path and budget constraint, provided the intersection occurs in the feasible set. If this intersection implies negative consumption, the agent's optimal bundle is $\left(0, p w^{x}+w^{y}\right)$ if $b<0$, and $\left(\left(p w^{x}+w^{y}\right) / p, 0\right)$ if $b>0$. Focusing on interior solutions, we have

$$
\begin{gathered}
x^{*}=\frac{p w^{x}+w^{y}+b}{a+p}, \\
y^{*}=\frac{a\left(p w^{x}+w^{y}\right)-p b}{a+p} .
\end{gathered}
$$

By Walras's Law, we need only consider the excess demand for good $x$. Individual excess demand is given by $x^{*}-w^{x}=m /(a+p)$, where $m=w^{y}+b-a w^{x}$, so aggregate excess demand is given by the equation

$$
Z_{x}(p)=\frac{m_{1}}{a_{1}+p}+\frac{m_{2}}{a_{2}+p}
$$

Assuming an interior, positive competitive equilibrium price exists (which is the case in our experiment parameterization by construction), we have

$$
p^{*}=-\frac{a_{1} m_{2}+a_{2} m_{1}}{m_{1}+m_{2}}
$$

For instability, we need $Z_{x}^{\prime}(p)>0$ when evaluated at $p^{*}$. (Note that excess demand returns to zero as $p$ approaches infinity, regardless of whether the interior competitive equilibrium is stable.) The derivative of excess demand with respect to $p$ is

$$
Z_{x}^{\prime}(p)=-\frac{m_{1}}{\left(a_{1}+p\right)^{2}}-\frac{m_{2}}{\left(a_{2}+p\right)^{2}} .
$$

Evaluating $Z_{x}^{\prime}$ at the interior equilibrium price, we have

$$
\begin{aligned}
Z_{x}^{\prime}\left(p^{*}\right) & =-\frac{m_{1}}{\left[\frac{m_{1}\left(a_{1}-a_{2}\right)}{m_{1}+m_{2}}\right]^{2}}-\frac{m_{2}}{\left[\frac{m_{2}\left(a_{2}-a_{1}\right)}{m_{1}+m_{2}}\right]^{2}} \\
& =-\left(\frac{m_{1}+m_{2}}{a_{1}-a_{2}}\right)^{2}\left(\frac{1}{m_{1}}+\frac{1}{m_{2}}\right) \\
& =-\frac{\left(m_{1}+m_{2}\right)^{3}}{m_{1} m_{2}\left(a_{1}-a_{2}\right)^{2}} .
\end{aligned}
$$

Thus $Z_{x}^{\prime}\left(p^{*}\right)>0$ if and only if

$$
\frac{\left(m_{1}+m_{2}\right)^{3}}{m_{1} m_{2}}<0 .
$$


Note from the aggregate excess demand equation that if $m_{1} m_{2}>0$ there does not exist an interior competitive equilibrium, because the sign of excess demand does not vary with price. Since we are restricting our attention to economies with at least one interior equilibrium, so that $m_{1} m_{2}<0$ by construction, the instability condition is met if and only if $m_{1}+m_{2}>0$.

Intuitively, this instability condition implies that agents have a relative preference for "home production." This is most readily seen in the case of corner endowments. If agent $2(1)$ is endowed only with good $y(x)$, then $m_{2}>0$ and $m_{1}<0$. Fixing $m_{2}$, we need $m_{1}$ sufficiently small to obtain instability, which in turn requires $a_{1}$ to be sufficiently small (an agent's relative preference for $x$ is decreasing in $a$ ). Graphically, if the endowment is near the lower-right (upper-left) corner of the Edgeworth box, for instability we need the expansion path for agent 1 to be flatter (steeper) than agent 2's.

Gale (1963) adopts the following parameter values:

$$
\begin{gathered}
a_{1}=\frac{1}{2}, \quad a_{2}=2, \quad b_{1}=b_{2}=0, \quad w_{1}^{x}=w_{2}^{y}=1-w_{1}^{y}=1-w_{2}^{x}=1 \\
\Rightarrow p^{*}=1, \quad m_{1}=-\frac{1}{2}, \quad m_{2}=1, \quad m_{1}+m_{2}=\frac{1}{2},
\end{gathered}
$$

hence, the instability result. Gale notes that if the endowments are switched, stability is obtained:

$$
\begin{gathered}
w_{1}^{x}=w_{2}^{y}=1-w_{1}^{y}=1-w_{2}^{x}=0 \\
\Rightarrow p^{*}=1, \quad m_{1}=1, \quad m_{2}=-2, \quad m_{1}+m_{2}=-1 .
\end{gathered}
$$

In the present paper, we adopt the following parameter values:

$$
\begin{aligned}
a_{1} & =\frac{1}{0.028167} \approx 35.5, \quad a_{2}=\frac{1}{0.00152} \approx 658, \\
b_{1} & =-\frac{38}{0.028167} \approx-1,349, \quad b_{2}=\frac{6}{0.00152} \approx 3,947, \\
w_{1}^{x} & =15, \quad w_{1}^{y}=400, \quad w_{2}^{x}=5, \quad w_{2}^{y}=5,600 \\
\Rightarrow p^{*} & =158, \quad m_{1} \approx-1,482, \quad m_{2}=6,258, \quad m_{1}+m_{2}=4,776,
\end{aligned}
$$

which implies the interior competitive equilibrium is unstable. Excess demand is drawn in Figure A1.

\section{B. A Broader Theoretical Framework for Gale's Example}

Gale's example features extreme disequilibrium price paths, but the underlying assumption that goods are perfect complements in consumption is not necessary to produce qualitatively similar dynamics. The Gale example can be viewed as the limiting case of a considerably broader set of smooth exchange economies.

Marshall $(1879$, p. 30) drew the diagram reproduced in Figure A2. This is a net trade diagram for a two-agent, two-good pure exchange economy, where the current 


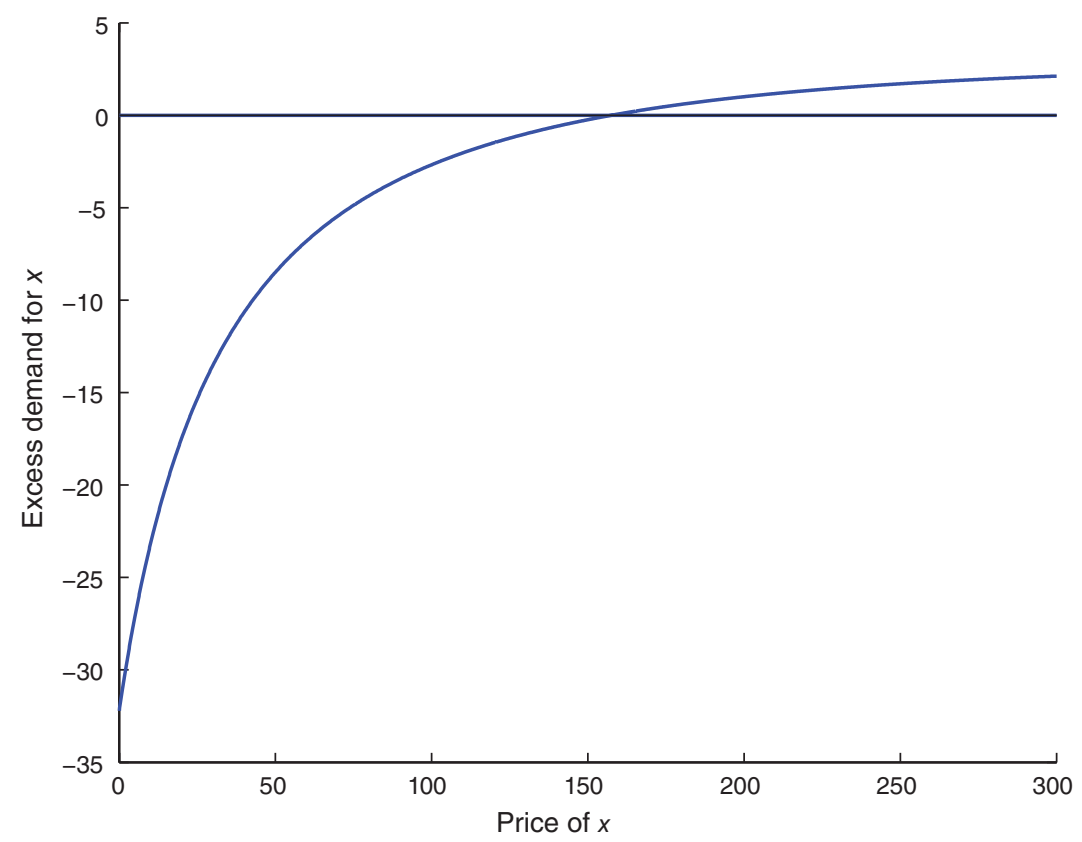

Figure A1. Excess Demand for Good $x$ IN THE EXPERIMENT

endowment is located at the origin. The (net) offer curve for England is labeled $E$, and Germany's is labeled $G$. In the example, England will sell good $x$ and Germany will sell good $y$; thus, any point $H=\left(H_{x}, H_{y}\right)$ reflects a net trade of $\left(-H_{x},+H_{y}\right)$ for England and $\left(+H_{x},-H_{y}\right)$ for Germany. The points $A, B$, and $C$ each represent equilibrium net trades. If we let good $y$ be the numeraire and $p(H)$ be the price of good $x$ implied by net trade $H$, then $p(A)>p(B)>p(C)$.

Marshall claims that $B$ is locally unstable, while $A$ and $C$ are locally stable. His argument uses what we now call Marshallian (as opposed to Walrasian) adjustment. Consider net trade proposal $P$, as labeled in Figure A2. To import $P_{x}$ units of $x$, Germany is not willing to pay a price greater than $p(Q)<p(P)$, so it is willing only to export fewer than $P_{y}$ units of $y$. Similarly, to import $P_{y}$ units of $y$, England is willing to accept a price as low as $p(R)<p(P)$, so it is willing to export more than $P_{x}$ units of $x$. Thus, a new proposal $H$ is made such that $H_{x}>P_{x}$ and $H_{y}<P_{y}$ (this proposal will occur in the region delineated by arrows in the diagram). Marshall argues that this process of allocation adjustment converges to net trade $C$. A similar story applies to net trade proposals in the region between $A$ and $B$, which eventually converge to $A$.

Walrasian adjustment also implies the stability of $A$ and $C$ (and the instability of $B)$. Consider price $p(Q)$. At this price, Germany's net demand for good $x, Q_{x}$, is less than England's net supply of good $x$, a quantity near $R_{x}$. Since aggregate excess demand at $p(Q)$ is negative, the price is adjusted downward, eventually converging to $p(C)$ and net trade $C$.

Offer curves similar to those drawn by Marshall in Figure A2 can be derived from CES or quasi-linear utility functions. For the CES function $u(x, y)=\left(\alpha x^{\rho}+\beta y^{\rho}\right)^{1 / \rho}$, Chipman (1965) provides a necessary condition for instability (and thus multiple equilibria), namely, $\rho<0$, which is intuitive considering that $\rho=1$ represents 


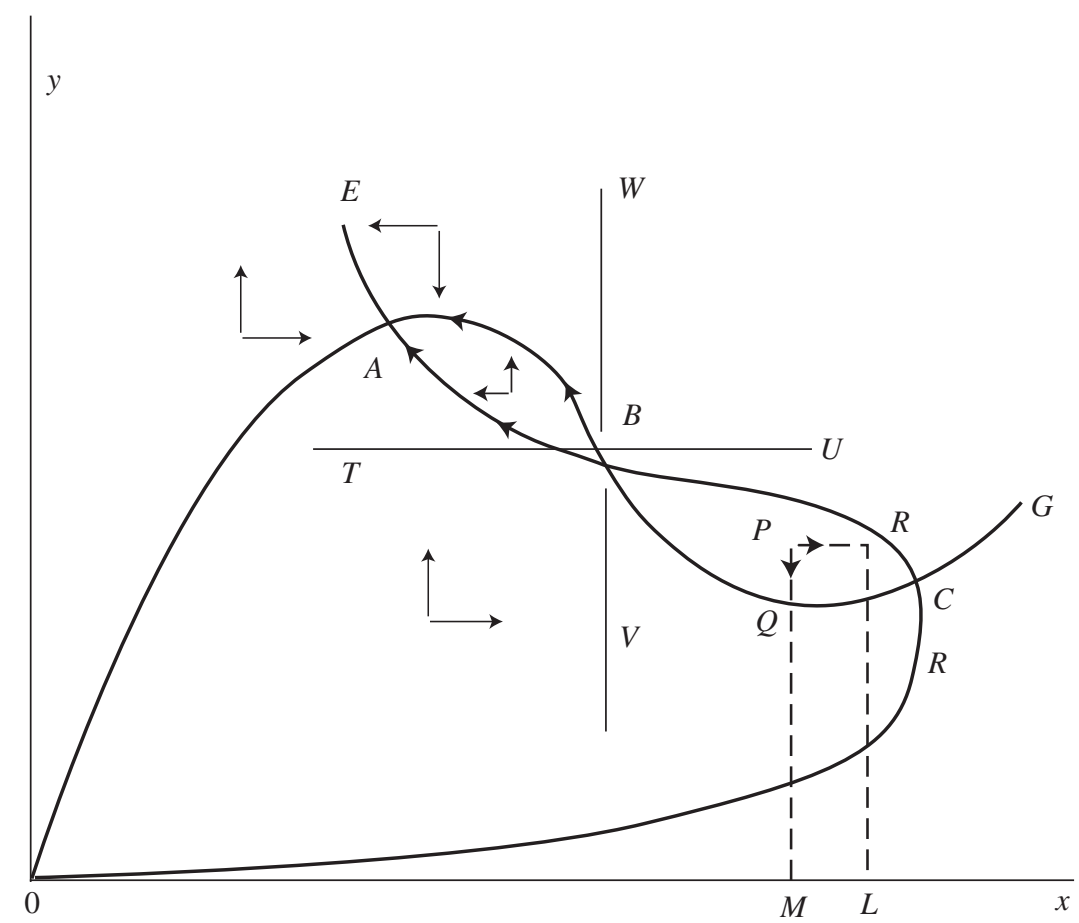

Figure A2. MARShall's (1879) ECONOMY

perfect substitutes, the limit as $\rho$ approaches zero represents Cobb-Douglas preferences, and the limit as $\rho$ approaches minus infinity represents the Leontief preferences we study in our experiment. ${ }^{\sqrt{26}}$ Analogous to our stability condition in the Gale example (i.e., $m_{1}+m_{2}>0$ ), instability for CES preferences generally also requires a taste for "home production" (e.g., England, the "exporter" of good $x$ in Marshall's example, needs a relatively high $\alpha$, and Germany a relatively high $\beta$ ).

Now, consider Marshall's economy as parameterized by CES preferences. Increasing the degree to which goods are complements (that is, decreasing $\rho$ ) moves the stable equilibrium allocations toward the axes of the net trade diagram, so that $p(A)$ increases, $p(C)$ decreases, and the gains from trade in these equilibria become more asymmetric. Gale's example is the limiting case where goods are perfect complements (i.e., the limit as $\rho \rightarrow \infty$ ). The unstable interior equilibrium survives as the only fixed point where markets clear: supply of $x$ exceeds demand whenever $p<p(B)$, pushing prices ever downward, while demand exceeds supply whenever $p>p(B)$, pushing prices ever upward. At a "corner" price of zero or infinity, the sign of aggregate excess demand is still nonzero but prices can move no further. When $p=0(\infty)$, England (Germany) gives away good $x(y)$ for free, while Germany (England) takes at least enough of it to satisfy its own demand but not so much so

\footnotetext{
${ }^{26}$ Chipman (2010) provides a tighter necessary condition for instability (namely, $\rho<1$ ) under the assumption that the CES economy is "supersymmetric" (i.e., endowments and preferences for the two agents are mirror images). Theodore C. Bergstrom, Ken-Ichi Shimomura, and Takehiko Yamato (2009) study conditions for multiple equilibria in two-agent, two-good economies with quasi-linear preferences.
} 
as to exceed England's (Germany's) supply. Such outcomes constitute competitive equilibria of a strange sort, where all of the gains from trade accrue to one side of the market, the beneficiary determined entirely by the initial price.

\section{REFERENCES}

Al-Ubaydli, Omar, John A. List, and Michael K. Price. 2010. "The Nature of Excess: Using Randomized Treatments to Investigate Price Dynamics.” National Bureau of Economic Research Working Paper 16319.

Alton, Michael R., and Charles R. Plott. 2007. "Principles of Continuous Price Determination in an Experimental Environment with Flows of Random Arrivals and Departures." California Institute of Technology, Division of the Humanities and Social Sciences, Working Paper 1276.

Anderson, Christopher M., Charles R. Plott, Ken-Ichi Shimomura, and Sander Granat. 2004. "Global Instability in Experimental General Equilibrium: The Scarf Example.” Journal of Economic Theory, 115(2): 209-49.

Arrow, Kenneth J., and Gerard Debreu. 1954. "Existence of an Equilibrium for a Competitive Economy." Econometrica, 22: 265-90.

Balogh, Thomas, and Paul Streeten. 1951. "The Inappropriateness of Simple 'Elasticity' Concepts in the Analysis of International Trade." Bulletin of the Oxford University Institute of Statistics, 13(3): $65-77$.

Bergstrom, Theodore C., Ken-Ichi Shimomura, and Takehiko Yamato. 2009. “Simple Economies with Multiple Equilibria." The B.E. Journal of Theoretical Economics, 9(1): Article 43.

Chipman, John. S. 1965. "A Survey of the Theory of International Trade: Part 2, the Neoclassical Theory." Econometrica, 33: 685-760.

Chipman, John S. 2010. "Multiple Equilibrium under CES Preferences." Economic Theory, 45(1-2): $129-45$.

Crockett, Sean, Ryan Oprea, and Charles R. Plott. 2011. "Extreme Walrasian Dynamics: The Gale Example in the Lab: Dataset." American Economic Review. http://www.aeaweb.org/articles. php?doi=10.1257/aer.101.7.3196.

Duffie, Darrell, and Hugo Sonnenschein. 1989. "Arrow and General Equilibrium Theory." Journal of Economic Literature, 27(2): 565-98.

Ferguson, Adam. 1767. An Essay on the History of Civil Society. Cambridge: Cambridge University Press, 2007.

Gale, David. 1963. “A Note on Global Instability of Competitive Equilibrium.” Naval Research Logistics Quarterly, 10(1), 81-87.

Gjerstad, Steven. 2007. "Price Dynamics in an Exchange Economy." Purdue University Economics Working Paper 1205.

Hahn, Frank H., and Takashi Negishi. 1962. "A Theorem on Non-Tatonnement Stability." Econometrica, 30: 463-69.

Hirota, Masayoshi, Ming Hsu, Charles R. Plott, and Brian W. Rogers. 2005. "Divergence, Closed Cycles and Convergence in Scarf Environments: Experiments in the Dynamics of General Equilibrium Systems." California Institute of Technology, Humanities and Social Sciences Working Paper 1239.

Hurwicz, Leonid, Roy Radner, and Stanley Reiter. 1975. "A Stochastic Decentralized Resource Allocation Process: Part I.” Econometrica, 43(2): 187-221.

Kirman, Alan. 1989. "The Intrinsic Limits of Modern Economic Theory: The Emperor Has No Clothes.” Economic Journal, 99(395): 126-39.

Marshall, Alfred. 1879. "The Pure Theory of Foreign Trade." Clifton, NJ: Augustus M. Kelley Publishers, 1974.

Plott, Charles R. 2000. "Market Stability: Backward-Bending Supply in a Laboratory Experimental Market: 1999 Presidential Address Western Economic Association." Economic Inquiry, 38(1): 1-18.

Plott, Charles R. 2001. "Equilibrium, Equilibration, Information and Multiple Markets: From Basic Science to Institutional Design." Paper presented at Nobel Symposium on Behavioral and Experimental Economics, Stockholm, Sweden.

Plott, Charles R., and Glen George. 1992. "Marshallian vs. Walrasian Stability in an Experimental Market." Economic Journal, 102(412): 437-60.

Plott, Charles R., and Jared Smith. 1999. "Instability of Equilibria in Experimental Markets: UpwardSloping Demands, Externalities, and Fad-Like Incentives." Southern Economic Journal, 65(3): $405-26$. 
Scarf, Herbert E. 1960. “Some Examples of Global Instability of the Competitive Equilibrium.” International Economic Review, 1: 157-72

Smith, Vernon L. 1965. "Experimental Auction Markets and the Walrasian Hypothesis." Journal of Political Economy, 73(4): 387-93.

Uzawa, Hirofumi. 1962. "On the Stability of Edgeworth's Barter Process." International Economic Review, 3: 218-32.

Walker, Donald A. 1996. Walras's Market Models. New York: Cambridge University Press.

Walras, Marie-Esprit-Léon. 1877. Elements of Pure Economics.Translated by Wiliam Jaffe, Cambridge, MA: Harvard University Press, 1954. 